\title{
ORIGINAL RESEARCH \\ Effect of a Ten-Week Short Message Service- Based Intervention on Self-Management of Type-2 Diabetes Patients in Bali, Indonesia
}

\author{
Made Rini Damayanti ${ }^{1}$, Gusti Ayu Ary Antari¹, Ni Luh Putu Nopriani ${ }^{1}$ \\ ${ }^{1}$ Department of Nursing, Faculty of Medicine, Udayana University, Indonesia
}

\begin{tabular}{l} 
Article Info \\
\hline Article History: \\
Received: 24 December 2020 \\
Revised: 23 June 2021 \\
Accepted: 13 July 2021 \\
Online: 27 August 2021 \\
Keywords: \\
Mobile health; self-management; \\
short message service; type 2 \\
diabetes \\
Corresponding Author: \\
Made Rini Damayanti \\
Department of Nursing, Faculty of \\
Medicine, Udayana University, \\
Indonesia \\
Email: \\
damayanti_maderini@unud.ac.id
\end{tabular}

damayanti_maderini@unud.ac.id

\begin{abstract}
Background: Diabetes mellitus is a chronic disease that may pose serious complications if poorly managed. The application of mobile technology (m-health) ranging from simple to more complex programs in diabetes management has the potential to foster patients' active involvement in their care. However, the evidence of $m$-health effectiveness on the self-management of type-2 diabetes patients in lowand middle-income countries is still mixed.

Purpose: This study aimed to evaluate the effect of a ten-week short message system (SMS)-based intervention (Tweek SMSDM) on self-management of type-2 diabetes patients.

Methods: A quasi-experimental study was performed in two groups. The intervention group $(\mathrm{n}=30)$ received additional daily automated messages to enhance their diabetic self-care practice, while the control group $(n=30)$ continued to follow the standard program only. Pre- and post-intervention data were measured in both groups using the Indonesian version of the Summary of Diabetes Self-Care Activities (SDSCA) questionnaire. T-test, Mann-Whitney, Wilcoxon Signed-Ranks, McNemar and Fisher exact tests were carried out to analyze the data. Results: After ten weeks, the intervention group showed significant mean changes in the domains of general diet $(0.42 \pm 1.08 ; p=0.034)$, specific diet $(1.75 \pm 1.42$; $p=0.0001)$, exercise $(1.02 \pm 1.85 ; p=0.005)$, blood-glucose testing ( $0.53 \pm 1.67$; $p=0.009)$, and foot care $(4.75 \pm 2.51 ; p=0.001)$ before and after the intervention, while the control group did not. This study also found significant differences in the mean scores for each domain of the SDSCA between the intervention and the control groups $(p<0.05)$.

Conclusion: The Tweek SMSDM program can improve the self-management of type-2 diabetes patients and positively affect each domain in the SDSCA. The findings of this study recommend that nurses integrate the program into patient treatment regimes in primary healthcare centers; therefore, patients and their significant others can play more proactive roles in their diabetic care.
\end{abstract}

How to cite: Damayanti, M. R., Antari, G. A. A., \& Nopriani, N. L. P. (2021). Effect of a ten-week short message service-based intervention on self-management of type-2 diabetes patients in Bali, Indonesia. Nurse Media Journal of Nursing, 11(2), 177-186. https://doi.org/10.14710/nmjn.v11i2.35257

\section{Introduction}

Diabetes mellitus is one of the four major non-communicable diseases (NCDs) that contributes to high mortality and morbidity rates worldwide (WHO, 2018). In 2017, diabetes mellitus was responsible for 4 million deaths globally, with $46.1 \%$ of these cases were found among people under the age of 60 (International Diabetes Federation, 2017). Data indicate that from 1980 to 2014, the number of adults living with diabetes increased fourfold from 108 million to 422 million, and it is estimated that the number will reach 629 million by 2045 (WHO, 2016). These statistics, however, may not reflect the actual figures since one in two persons with diabetes in 2017 (212.4 million) was undiagnosed (International Diabetes Federation, 2017).

The escalating prevalence of diabetes is higher in lower-income to middle-income countries, such as Indonesia, compared to high-income countries. Of $73 \%$ of deaths attributable to NCDs during 2016 in Indonesia, 6\% was caused by diabetes (WHO, 2018). Apart from the Indonesian government's efforts to overcome the problem, it is predicted that Indonesia will have more people living with diabetes by 2045 , reaching 16.7 million in number with predominantly type-2 diabetes mellitus (International Diabetes Federation, 2017). These trends might indicate the existence of patient-related, healthcare system, financial, and logistical barriers to comply with 
currently available national guidelines for managing the disease (Horigan et al., 2017; Venkataraman et al., 2009). Therefore, there is an urgent need to develop a more efficient diabetes care strategy that is more cost-effective, easily accessible, and contextually appropriate to improve the outcomes.

Owing to the chronic nature of diabetes, the disease may pose serious complications if poorly managed. Patients' active involvement in their diabetes care has a pivotal role in the prognosis of the disease (Andriyanto et al., 2019; Holtz \& Lauckner, 2012; Mulvaney et al., 2012). Patients' contribution can only be achieved if patients are fully informed; therefore, delivering a diabetes education program to promote self-care in managing their disease termed self-management is crucial (Funnell et al., 2010). Self-management plays a critical role in complementing a pharmacological approach to prevent further complications and increase the patients' overall health outcomes (Hailu et al., 2019) by fostering their self-efficacy, self-perception, and effective diabetes-related coping strategies (Sayeed et al., 2020). Self-management interventions targeting people with diabetes will eventually assist them so they can actively engage in managing the disease symptoms, treatments, lifestyle adjustments, and non-physiological consequences of the disease, and be fully competent in making informed decisions (Hailu et al., 2019; Powers et al., 2017).

One of the most commonly cited diabetes care interventions to support patients' selfmanagement is the application of information technology through the mobile health (m-Health) system (Gatwood et al., 2016). These interventions make use of the mobile communication devices owned by the targets to deliver information relevant to disease management (Arora et al., 2012). To be successfully implemented, m-Health must be technologically appropriate in that it must employ a basic technology that is familiar to the target population, easily accessible, and understandable (Peimani et al., 2016). Previous studies concluded that in lower-income to middle-income countries, particularly those with limited access to advance technology and the internet, broadcasting Short Message Service (SMS) messages is considered to be the most feasible and effective strategy to educate and empower patients to take care of themselves, improve adherence to treatment/medication, and foster their self-efficacy (Abaza \& Marschollek, 2017; Van Olmen et al., 2017). The SMS-based intervention is simpler and also safer in protecting the users' privacy than any others $m$-health application because it is delivered to an individual's target private message inbox and can be easily received or deleted (Rathbone \& Prescott, 2017).

In Indonesia, based on the data retrieved from the Ministry of Communications and Information Technology, the number of mobile phone subscribers up to 2017 reached 435.19 million (The Central Bureau of Statistics of Indonesia, 2018). This figure may indicate that Indonesians are already familiar with mobile phone technology and that mobile phone use has infiltrated diverse elements of society regardless of social status. Thus, mobile phone technology has a great potential to be used to disseminate health information among this population. Nevertheless, little is known regarding the role of $m$-health application in supporting selfmanagement practice in type-2 diabetes patients in Indonesia. Interviews with the primary healthcare nurses (PHNs) working in several primary healthcare centers (PHCs) in Bali during the preliminary study yielded meaningful information that provided a strong background to conduct the current study. The PHNs expressed time constraints to educate the diabetic patients in enough detail as their biggest concern when caring for those patients. The PHNs also found that many patients did not fully understand their condition and how to manage it, which eventually resulted in failure to maintain their health status.

This study was conducted to fill the gap by evaluating the effect of a technologically and contextually appropriate intervention, called Tweek SMSDM for short, in which automated SMS messages were sent using an open-access software to individual patients living in an urban area in Bali for ten weeks' duration. This technology was selected based on the pre-assessment undertaken with the targeted population and the PHNs. Two months before commencing the program, the PHNs were requested to inform the patients during their monthly visit to the PHC regarding the program and asked them to choose the most preferred m-health technology to be implemented. Of the total 30 patients, 28 (93.33\%) persons opted for SMS due to its familiarity, comfortability, and accessibility. A discussion with the PHNs further justified this option because the type-2 diabetic patients in the present study were dominated by those aged around 60 years old, where most of them were known to use the cell phone instead of a smartphone. Therefore, 
the purpose of the current study was to evaluate the effect of a ten-week short message servicebased intervention (Tweek SMSDM) on the self-management of type-2 diabetes patients.

\section{Methods}

\subsection{Research design}

This study was a quasi-experimental study performed in two groups: an intervention group following the Tweek SMSDM program and a control group following the standard diabetes management program (i.e., a monthly visit to the patients' respective PHCs).

\subsection{Setting and samples}

Participants were recruited from 11 PHCs across an urban area in Bali, Indonesia. Userfriendly information sheets informing the nature of the study were distributed to the targeted PHCs. In each PHC, a research assistant, who was a registered nurse working in the PHC, was tasked to recommend type-2 diabetes patients to participate in this study. Patients with the following inclusion criteria were eligible to be included in this study: being an adult, having type2 diabetes, having a personal mobile phone, and being familiar with the texting function. Patients were excluded when they were unable to provide informed consent and had a history of psychiatric illness. From 75 patients recruited by the research assistants, 69 stated their willingness to participate in this study, but only 60 met the final eligibility criteria. Eligible patients were given informed consent forms and were blindly randomized using a random number generator into either the intervention group (30 patients) or the control group (30 patients).

\subsection{Intervention}

The Tweek-SMSDM intervention is a contextually appropriate, low-cost, and unidirectional program using basic mobile phone functions. Using a free open access SMS management software, an automated SMS message was sent three times daily (at 8 a.m., 11.30 a.m., and 6 p.m.) to each participant in the intervention group for ten weeks' duration. Each SMS consisted of a maximum of 160 characters. An example of the message: "Simple actions to stay healthy: eat healthily, physically active, check blood sugar \& take meds regularly, avoid smoking \& balance your life. You can do it!". Weekly trivia quizzes were given to the participants in the intervention group. The control group neither received the SMSs nor the quizzes. The PHNs were fully informed about the program and they provided constructive feedbacks along the process of intervention. By doing so, ensuring that our participating patients received information only through our program to reduce the chance of contamination could be maintained, as well as providing educational content that suited well with their needs.

The intervention consisted of continued education, reminders and reinforcement of diet, exercise counseling, foot care counseling, blood-glucose monitoring, medication-taking reminders, and additional information related to healthy habits for diabetes patients (see Table 1). Medication reminders were also incorporated into the messages. The SMS contents were designed mainly based on the diabetes management consensus of the Indonesian Endocrinology Association (Rudijanto et al., 2011) and the SDSCA's components (Toobert et al., 2000) to motivate, educate, remind, and empower patients to manage their disease. The text messages were designed to have direct and indirect influences on patients' self-management practices. The direct influence would come from the messages containing reminders and the indirect influence from the messages that increase social support, foster self-efficacy, and modify beliefs on health. Frequent messages sent daily from an automated SMS will modify patients' health beliefs and simultaneously increase the perceived social support. Self-efficacy will be improved through feedback on patients' self-management practices. Self-efficacy will also mediate the impact of social support on self-management. Eventually, self-management will, in turn, modify health beliefs by decreasing perceived barriers and boost patients' self-efficacy through their experience in managing the disease (Nundy et al., 2013).

\subsection{Measurement and data collection}

The data collection was conducted from January to March 2020. A week before commencing the intervention, both groups were measured at the baseline using a paper-based questionnaire during their visit to their respective PHC. The data was collected with the help of the PHNs in 
every targeted PHC. It was conducted to gather information on their sociodemographic characteristics and general information that included age, gender, marital status, level of education, employment, medication intake, years of having diabetes, years of owning a cell phone and comfort levels of using its texting and calling functions. The questionnaire also consisted of an assessment of patients' self-management practices using the revised version of The Summary of Diabetes Self-Care Activities Measure (SDSCA). The revised version of the SDSCA is an elevenitem brief and a valid self-report instrument to identify the level of self-management in five regime domains, namely diet (item 1 to 4 ), exercise (item 5 to 6), blood-glucose testing (item 7 to 8), foot care (item 9 to 10), and smoking (item 11). The SDSCA questionnaire asks the respondents to state their self-care activities during the past 7 days. The response options for items 1 to 10 are rated on an eight-point Likert scale from zero ("don't do it at all") to seven ("complete it all"). The first four subscales are scored by calculating the mean number of days per week from the relevant items with higher scores corresponding better self-management practice. The eleventh item is a binary question that indicates an individual's smoking status (o for "no" and 1 for "yes") and the average number of cigarettes smoked per day (Toobert et al., 2000). Access and permission to use the instrument were granted by the developers. The Indonesian version of the SDSCA has shown satisfying psychometric properties with the Cronbach's alpha of 0.72 and content validity of 0.98 (Sh et al., 2019). After the completion of the program, endpoint measurement was performed at the week eleventh on the intervention and control groups.

Table 1. Contents of the ten-week short message service-based intervention

\begin{tabular}{|c|c|c|c|}
\hline Items & Topics & Subtopics & Time \\
\hline Part 1 & $\begin{array}{l}\text { General } \\
\text { information about } \\
\text { diabetes }\end{array}$ & $\begin{array}{ll}\text { 1. } & \text { Definition } \\
\text { 2. } & \text { Risk factors } \\
\text { 3. } & \text { Signs and symptoms } \\
\text { 4. } & \text { Management and treatment } \\
\text { 5. } & \text { Prognosis } \\
\text { 6. } & \text { Complication } \\
\text { 7. } & \text { Utilization of healthcare facilities } \\
\text { 8. } & \text { The importance of self-management }\end{array}$ & $\begin{array}{l}\text { Covered on week } 1 \\
\text { and repeated on } \\
\text { week } 6 \text { to } 10\end{array}$ \\
\hline Part 2 & Healthy diet & $\begin{array}{ll}\text { 1. } & \text { Balanced diet } \\
\text { 2. } & \text { Healthy foods } \\
\text { 3. } & \text { Substitution foods } \\
\text { 4. } & \text { Food composition } \\
\text { 5. } & \text { Calories need } \\
\text { 6. } & \text { Food preparation } \\
\text { 7. } & \text { Healthy cooking methods } \\
\text { 8. } & \text { Eating schedules }\end{array}$ & $\begin{array}{l}\text { Covered on week } 2 \\
\text { and repeated on } \\
\text { week } 6 \text { to } 10\end{array}$ \\
\hline Part 3 & $\begin{array}{l}\text { "Get moving" } \\
\text { physical activities }\end{array}$ & $\begin{array}{ll}\text { 1. } & \text { Types of physical activity } \\
\text { 2. } & \text { Preparations } \\
\text { 3. } & \text { Targets } \\
\text { 4. } & \text { Duration and frequency } \\
\text { 5. } & \text { Contraindications } \\
\text { 6. } & \text { Tips for overcoming barriers } \\
\text { 7. } & \text { Foot care }\end{array}$ & $\begin{array}{l}\text { Covered on week } 3 \\
\text { and repeated on } \\
\text { week } 6 \text { to } 10\end{array}$ \\
\hline Part 4 & $\begin{array}{l}\text { "Self-check" blood } \\
\text { glucose } \\
\text { monitoring }\end{array}$ & $\begin{array}{l}\text { 1. The importance } \\
\text { 2. Timing } \\
\text { 3. Practice guidance } \\
\text { 4. Interpret the results }\end{array}$ & $\begin{array}{l}\text { Covered on week } 4 \\
\text { and repeated on } \\
\text { week } 6 \text { to } 10\end{array}$ \\
\hline Part 5 & $\begin{array}{l}\text { Additional } \\
\text { information }\end{array}$ & $\begin{array}{ll}\text { 1. } & \text { Avoid smoking } \\
\text { 2. } & \text { Weight control } \\
\text { 3. } & \text { Stress management }\end{array}$ & $\begin{array}{l}\text { Covered on week } 5 \\
\text { and repeated on } \\
\text { week } 6 \text { to } 10\end{array}$ \\
\hline
\end{tabular}

\subsection{Data analysis}

Descriptive statistics were carried out to identify the data gathered at the baseline. Independent t-test and chi-square test were used to test the homogeneity of the characteristics between the intervention and control groups. Baseline differences in the SDSCA subscales between the two groups were also analyzed using the independent t-test, except the blood-glucose 
testing, which was analyzed using the non-parametric Mann-Whitney test as the data were not normally distributed. Post-intervention data were analyzed using a paired t-test for the data that were normally distributed and a Wilcoxon Signed-Ranks test for the data that were not normally distributed. For all statistical assessments, a two-sided p-value less than 0.05 was considered statistically significant.

\subsection{Ethical considerations}

Ethical approval to conduct the study was received from the Research Ethics Committee of Udayana University and Sanglah Hospital (1839/UN.14.2/Litbang/2020). All participants provided informed consent, and their anonymity was preserved. Access to the target population and permission to perform the study in Bali, Indonesia, was granted by the local authorities.

\section{Results}

3.1 Characteristics of particpants

This study included 60 subjects at the baseline and a ten-week follow-up. Table 2 shows that the intervention and control groups were homogenous $(p>0.05)$. The mean age of the intervention group was 61.03 years, while that of the control group was 61.20 years. Male and female subjects were distributed evenly between the two groups so that each group consisted of $50 \%$ male subjects and 50\% female subjects. The majority of the subjects in both groups were married (intervention $86.7 \%$, control $90 \%$ ), graduated from primary education (intervention $46.7 \%$, control 50\%), were unemployed (intervention $46.7 \%$, control $43.3 \%$ ), and were on oral hypoglycemic agent medication (intervention 83.3\%, control 80\%). The duration of diabetes varied largely in both groups. All participants indicated being comfortable using basic texting features (receiving and creating messages).

Table 2. Demographic characteristics of respondents $(n=60)$

\begin{tabular}{|c|c|c|c|c|c|}
\hline Characteristics & $\begin{array}{l}\text { Intervention } \\
\text { Mean(SD) }\end{array}$ & $\begin{array}{l}\text { Control } \\
\text { Mean(SD) }\end{array}$ & $\begin{array}{l}\text { Intervention } \\
\mathrm{f}(\%)\end{array}$ & $\begin{array}{l}\text { Control } \\
\mathrm{f}(\%)\end{array}$ & $p$ \\
\hline Age (year) & $61.03(8.58)$ & $61.20(7.10)$ & & & $0.935^{*}$ \\
\hline Gender, & & & & & $1.000^{1}$ \\
\hline Male & & & $15(50)$ & $15(50)$ & \\
\hline Female & & & $15(50)$ & $15(50)$ & \\
\hline Marital status & & & & & $1.000^{x}$ \\
\hline Married & & & $26(86.7)$ & $27(90)$ & \\
\hline Separated/divorced/widowed & & & $4(13.3)$ & $3(10)$ & \\
\hline Education & & & & & $0.839^{€}$ \\
\hline Primary school graduate & & & $14(46.7)$ & $15(50)$ & \\
\hline Senior high school graduate & & & $9(30)$ & $7(23.3)$ & \\
\hline College graduate or higher & & & $7(23.3)$ & $8(26.7)$ & \\
\hline Employment & & & & & $0.938^{€}$ \\
\hline Employed & & & $11(36.7)$ & $11(36.7)$ & \\
\hline Unemployed & & & $14(46.7)$ & $13(43.3)$ & \\
\hline Retired & & & $5(16.6)$ & $6(20)$ & \\
\hline Medication & & & & & $1.000^{\ddagger}$ \\
\hline Oral hypoglycemia agents & & & $25(83.3)$ & $24(80)$ & \\
\hline Insulin & & & $5(16.7)$ & $6(20)$ & \\
\hline Years of Diabetes Mellitus & & & & & $0.852^{€}$ \\
\hline$\leq 5$ years & & & $13(43 \cdot 3)$ & $12(40)$ & \\
\hline 6-10 years & & & $9(30)$ & $8(26.7)$ & \\
\hline$>10$ years & & & $8(26.7)$ & $10(33.3)$ & \\
\hline $\begin{array}{l}\text { Comfort level making/ } \\
\text { receiving textings }\end{array}$ & & & & & - \\
\hline Very or somewhat comfortable & & & $30(100)$ & $30(100)$ & \\
\hline $\begin{array}{l}\text { Comfort level making/ } \\
\text { receiving calls }\end{array}$ & & & & & $1.000^{x}$ \\
\hline Very or somewhat comfortable & & & $25(83.3)$ & $26(86.7)$ & \\
\hline Not comfortable & & & $5(16.7)$ & $4(13.3)$ & \\
\hline Years of owning a cell phone & & & & & $0.852^{€}$ \\
\hline$\leq 5$ years & & & $10(33.3)$ & $8(26.7)$ & \\
\hline 6-10 years & & & $12(40)$ & $13(43.3)$ & \\
\hline$>10$ years & & & $8(26.7)$ & $9(30)$ & \\
\hline
\end{tabular}

Notes. ${ }^{*}$ Independent t-test, ${ }^{\mathrm{t}}$ Continuity Correction, ${ }^{x}$ Fisher's Exact test, ${ }^{€ P e a r s o n}$ Chi-Square

Copyright (C) 2021, NMJN, e-ISSN 2406-8799, p-ISSN 2087-7811 


\subsection{Comparison of self-management assessed by the Summary of Diabetes Self-Care Activities Measure}

Table 3 shows mean score changes in each domain of the SDSCA in intervention and control groups before and after the Tweek SMSDM program. There were significant differences in the mean scores for each of the domains of the SDSCA between the intervention and the control groups $(p<0.05)$, except for smoking status. Changes in mean scores also indicate that, on average, the patients in the intervention group have increased their ability to perform activities listed on the SDSCA instrument for 1-5 days in any given week. The mean score changes in each domain can be outlined as follow: $0.42(\mathrm{SD}=1.08)$ for general diet, $1.75(\mathrm{SD}=1.42)$ for specific diet, $1.02(\mathrm{SD}=1.85)$ form exercise, $0.53(\mathrm{SD}=1.67)$ for blood-glucose testing, and $4.75(\mathrm{SD}=2.51)$ for foot care.

Table 3. Differences in the mean score changes of the diabetes self-management practice between groups $(n=60)$

\begin{tabular}{|c|c|c|c|c|c|}
\hline Domains & $\begin{array}{l}\text { Intervention } \\
\text { Mean(SD) }\end{array}$ & $\begin{array}{c}\text { Control } \\
\text { Mean(SD) }\end{array}$ & $\begin{array}{c}\text { Intervention } \\
\mathrm{f}(\%)\end{array}$ & $\begin{array}{c}\text { Control } \\
\mathrm{f}(\%)\end{array}$ & $p$ \\
\hline \multicolumn{6}{|l|}{ SDSCA } \\
\hline General diet & $0.42(1.08)$ & $-0.13(0.54)$ & & & $0.016^{*}$ \\
\hline Specific diet & $1.75(1.42)$ & $-0.02(0.38)$ & & & $0.0001^{*}$ \\
\hline Exercise & $1.02(1.85)$ & 0.07 (0.29) & & & $0.007^{*}$ \\
\hline Blood-glucose testing & $0.53(1.67)$ & $-0.03(0.49)$ & & & $0.0001^{£}$ \\
\hline Foot care & $4.75(2.51)$ & $0.20(0.64)$ & & & $0.0001^{*}$ \\
\hline $\begin{array}{l}\text { Smoking status post } \\
\text { intervention }\end{array}$ & & & & & $1.000^{x}$ \\
\hline Yes & & & $\mathrm{o}(0.0)$ & $1(3.3)$ & \\
\hline No & & & $30(100)$ & $29(96.7)$ & \\
\hline
\end{tabular}

*Independent t-test, ${ }^{£}$ Mann-Whitney test, ${ }^{\infty}$ Fisher’s Exact test

Table 4 shows within-group post-intervention differences from the baseline in the selfmanagement practices between the groups being compared. After ten weeks, improvements in all domains of the SDSCA were apparent in the intervention group. Statistical improvement was observed in the domains of general diet $(0.42 \pm 1.08 ; p=0.034)$, specific diet $(1.75 \pm 1.42$; $p=0.0001)$, exercise $(1.02 \pm 1.85 ; p=0.005)$, blood-glucose testing $(0.53 \pm 1.67 ; p=0.009)$, and foot care $(4.75 \pm 2.51 ; p=0.001)$, while there were no significant mean changes in the control group $(p>0.05)$. In the smoking status domain, no significant difference in proportion was found before and after intervention $(p=1.00)$.

Table 4. Differences in the diabetes self-management practice within each group pre-post intervention $(\mathrm{n}=30)$

\begin{tabular}{|c|c|c|c|c|c|c|}
\hline \multirow[t]{2}{*}{ Domains } & \multicolumn{2}{|c|}{ Intervention $(\mathrm{n}=30)$} & \multirow{2}{*}{$p$} & \multicolumn{2}{|c|}{ Control $(\mathrm{n}=30)$} & \multirow{2}{*}{$p$} \\
\hline & Pre & Post & & Pre & Post & \\
\hline SDSC, mean (SD) & & & & & & \\
\hline General diet & $6.32(0.83)$ & $6.73(0.92)$ & $0.034^{1}$ & $6.23(0.93)$ & $6.10(1.04)$ & $0.197^{\dagger}$ \\
\hline Specific diet & $4.93(1.42)$ & $6.68(0.46)$ & $0.0001^{*}$ & $4.93(1.33)$ & $4.92(1.30)$ & $0.813^{*}$ \\
\hline Exercise & $5.55(1.57)$ & $6.57(0.94)$ & $0.005^{*}$ & $5.58(1.49)$ & $5.65(1.36)$ & $0.211^{*}$ \\
\hline Blood-glucose testing & $0.72(1.39)$ & $1.25(1.10)$ & $0.009^{1}$ & $0.93(1.34)$ & $0.90(1.47)$ & $0.705^{\mathrm{t}}$ \\
\hline Foot care & $2.08(2.43)$ & $6.83(0.65)$ & $0.0001^{*}$ & $2.12(2.44)$ & $2.32(2.24)$ & $0.097^{*}$ \\
\hline Smoking status, $\mathrm{f}(\%)$ & $1(3.3)$ & $\mathrm{o}(\mathrm{o})$ & - & $1(3.3)$ & $1(3.3)$ & $1.00^{¥}$ \\
\hline
\end{tabular}

*Paired t-test, ${ }^{+}$Wilcoxon Signed Ranks test, ${ }^{\ddagger}$ McNemar’s test

\section{Discussion}

There has been a dearth of literature examining the effectiveness of the $\mathrm{m}$-Health technology application on self-management practices among patients with type-2 diabetes from the Indonesians' perspective. The present study attempted to bridge this gap by evaluating the impact of a ten-week automated text-message-based diabetes self-management program on patients' self-care practices in managing their disease, measured using the revised version of the SDSCA instrument. Patients' ability to perform self-management will eventually improve their health outcomes by preventing complications or slowing the disease progression (Holtz \& Lauckner, 2012; Mulvaney et al., 2012; Pamungkas et al., 2015). 
In the present study, positive trends towards the improvement of self-management practices were evident within the intervention group. This study is consistent with the previous studies conducted in other countries, which found that using contextually appropriate technology by broadcasting text messages to people living with diabetes in lower-income to middle-income countries was effective to improve their self-management level (Abaza \& Marschollek, 2017; Arora et al., 2012; Van Olmen et al., 2017). The effectiveness of the program in the current study might also be influenced by the broad array of information covered in the text messages. Researchers designed the contents of the Tweek SMSDM program based on the evidence-based practice guidelines that had been implemented in the local healthcare centers (Rudijanto et al., 2011). Furthermore, the intensive text messages that were sent three times daily for ten weeks' duration might alter patients' health beliefs and provided an easily accessible support system as perceived by the type-2 diabetes patients (Nundy et al., 2013). In each text message, encouraging sentences were applied to provide positive reinforcement for the patients. The purpose was to increase patients' self-efficacy, which is known to be an antecedent to patients' self-management (Nundy et al., 2013; Richard \& Shea, 2011). Self-efficacy will also mediate the impact of social support on self-management (Nundy et al., 2013).

In this study, SDSCA scores across all domains in the intervention group showed a trend of improvement after the Tweek SMSDM program, with the highest improvement in the foot care domain. Contrastingly, the general diet domain showed the lowest mean score improvement. However, it should be taken into consideration that the scores for general diet among the participants in the intervention group were already high at the baseline measurement. A study by Nundy et al. (2013) also showed a positive impact of text message-based interventions on diabetes patients' foot care practice under a six-month $\mathrm{m}$-Health project. The improvement in the foot care domain's score might be due to the foot care procedure being generally simple. Foot care could be carried out without any complex lifestyle or environmental modifications and implemented routinely without consuming much time. In this study, the patients were also reminded of the importance of foot monitoring and choosing comfortable and supportive footwear.

The findings in the diet domains could be explained by the impact of people's social and cultural backgrounds on their diet patterns. Cultural backgrounds and religious beliefs influence people's food preferences (Shipman \& Durmus, 2017). In this study, the findings in the diet domains might also be explained by the present study's population demographic characteristics. The average age of the participants in this study was 6o years, and most of them were already retired, so their dietary habits could have been greatly influenced by the habits in their families. In this case, families could provide a support system for diabetes patients that contributed to their adherence to the recommended diet plan and physical activity (Pesantes et al., 2018; Rahmah et al., 2019). This study also found that the patients in the intervention group were showing a significant change in the specific diet domain score. This result could be associated with the Balinese cultural background, where there are various local events and activities that use fruits as the primary food items for material offerings (Adiputra, 2017; Sujarwo et al., 2020).

Another important finding in this study was not only that all respondents in both groups expressed being comfortable with using basic texting features such as receiving and creating messages, but also the fact that no respondent dropped out of the study. This indicates the feasibility of implementing an SMS-based intervention among patients with type-2 diabetes in Indonesia, particularly in Bali. A systematic review by Peiris et al. (2014) concluded that m-Health was promising for health care support such as behavioral management in non-communicable disease patients in lower-income and middle-income countries. The present study sent the SMSbased interventions in conjunction with maintaining the standard/conventional diabetes management recommended by the respective PHC. This might also explain why all the respondents stayed until the end of the program. Also, it is important to note that the majority of the respondents in both groups were unemployed or already retired, so they were enthusiastic about completing the ten-week intervention program and integrating the application of textmessage technology with which they were already familiar into their disease management.

\section{Implication and limitation}

The findings of this study have crucial implications, not only for diabetes patients but also for their significant others and health care providers, particularly nurses, on how to better support people living with diabetes to maintain their health status. Healthcare providers working with 
diabetes patients in PHCs or any settings could adopt the application of this simple yet effective technology in their daily practice to overcome barriers that they may encounter. Support from relevant stakeholders is also necessary to integrate the application of this kind of technology into the healthcare system. More importantly, patients and their significant others should proactively engage to manage the disease by seeking and adhering to reliable health information given by trusted parties, so that positive outcomes of disease management can be achieved.

The primary limitation of this study could be the absence of intermediate assessments before the endpoint evaluation on the tenth week, which might have had significant practical and financial implications. Also, a unidirectional text-message system was implemented, which made it impossible to provide information tailored to specific patients' needs. In this study, we also fully relied on patients' self-reported information; therefore we could not completely ensure that they performed the recommended regimes appropriately. These warrant directions for future studies. However, the present study has yielded evidence gathered from the field regarding the effect of a contextually appropriate $m$-health application to address the current practice need on improving diabetics patients' involvement to manage the disease in Indonesia, particularly in Bali.

\section{Conclusion}

Patients' active involvement is a cornerstone for successful diabetes mellitus management. Therefore, it is necessary to foster patients' awareness, knowledge, and capacity on diabetes selfcare practice by employing a simple, cost-effective, easily accessible, and contextually appropriate intervention. The present study indicates that using a basic function of the mobile phone technology can improve diabetes patients' self-management practice in the areas of general information about the disease, healthy diet, recommended physical activity and foot care practice, blood-glucose monitoring, and so on. The findings of this study recommend for nurses to better support people living with diabetes, particularly in community settings, by integrating the program into patient treatment regimes in primary healthcare centers. Therefore, patients and their significant others can play more proactive roles in managing their disease to prevent further complications and improve their health outcomes. Further studies of integrating mobile technology applications into diabetes care are also recommended by taking the limitations of the current study into account. First, it is necessary to conduct a series of program evaluations, including the long-term assessment that is not only focusing on the program's effectiveness but also on how the targets perceive it. Second, it might consider implementing tailored and bidirectional message services to address specific patients' needs. Finally, it should consider integrating strategies to monitor targets' compliance more objectively, such as behaviors observation or the measurement of diabetes makers.

\section{Acknowledgment}

The researchers wish to thank all the participating diabetes patients from the primary healthcare centers for their valuable contribution in this study. Additionally, the researchers thank the PHC nurses for providing assistance during the study. Tweek SMSDM was supported by a research grant from the Directorate General of Research, Technology, and Higher Education of the Ministry of Research, Technology, and Higher Education of Indonesia in 2020.

\section{Author contribution}

All authors contributed to the study conception and design (MRD and GAAA), data collection (MRD and NLPN), data analysis (MRD and GAAA), manuscript writing and revision for important intellectual content (MRD, GAAA and NLPN). All authors read and approved the final manuscript.

\section{Conflict of interest}

The authors declare no conflict of interest

\section{References}

Abaza, H., \& Marschollek, M. (2017). SMS education for the promotion of diabetes selfmanagement in low \& middle income countries: A pilot randomized controlled trial in Egypt. BMC Public Health, 17(1), 962. https://doi.org/10.1186/s12889-017-4973-5 
Adiputra, I. N. (2017). Fungsi buah dan daun tanaman dalam budaya bali sebuah kajian terhadap tanaman upacara [Functions of fruits and leaves of plants in balinese culture: A study of ceremonial plants]. Bumi Lestari Journal of Environment, 17(2), 118. https://doi.org/10.24843/blje.2017.v17.io2.po3

Andriyanto, A., Rekawati, E., \& Rahmadiyah, D. C. (2019). Increasing knowledge, attitudes, skills, and glucose control in type-2 diabetic patients through EMAS interventions. Nurse Media Journal of Nursing, 9(2), 141-150. https://doi.org/10.14710/NMJN.V9I2.22989

Arora, S., Peters, A. L., Agy, C., \& Menchine, M. (2012). A mobile health intervention for inner city patients with poorly controlled diabetes: Proof-of-concept of the TExT-MED program. Diabetes Technology and Therapeutics, 14(6), 492-496. https://doi.org/10.1089/dia.2011.0252

Funnell, M. M., Brown, T. L., Childs, B. P., Haas, L. B., Hosey, G. M., Jensen, B., Maryniuk, M., Peyrot, M., Piette, J. D., Reader, D., Siminerio, L. M., Weinger, K., \& Weiss, M. A. (2010). National standards for diabetes self-management education. Diabetes Care, 33(Supplement 1), S89-S96. https://doi.org/10.2337/dc10-So89

Gatwood, J., Balkrishnan, R., Erickson, S. R., An, L. C., Piette, J. D., \& Farris, K. B. (2016). The impact of tailored text messages on health beliefs and medication adherence in adults with diabetes: A randomized pilot study. Research in Social and Administrative Pharmacy, 12(1), 130-140. https://doi.org/10.1016/j.sapharm.2015.04.007

Hailu, F. B., Moen, A., \& Hjortdahl, P. (2019). Diabetes self-management education (DSME) effect on knowledge, self-care behavior, and self-efficacy among type 2 diabetes patients in Ethiopia: A controlled clinical trial. Diabetes, Metabolic Syndrome and Obesity: Targets and Therapy, 12, 2489. https://doi.org/10.2147/DMSO.S223123

Holtz, B., \& Lauckner, C. (2012). Diabetes management via mobile phones: A systematic review. Telemedicine and E-Health, 18(3), 175-184. https://doi.org/10.1089/tmj.2011.0119

Horigan, G., Davies, M., Findlay-White, F., Chaney, D., \& Coates, V. (2017). Reasons why patients referred to diabetes education programmes choose not to attend: A systematic review. Diabetic Medicine, 34(1), 14-26. https://doi.org/10.1111/dme.13120

International Diabetes Federation. (2017). IDF diabetes atlas (8th ed.). https://diabetesatlas.org/en/resources/.

Mulvaney, S., Anders, S., Smith, A., Pittel, E., \& Johnson, K. (2012). A pilot test of a tailored mobile and web-based diabetes messaging system for adolescents. Journal of Telemedicine and Telecare, 18(2), 115-118. https://doi.org/10.1258/JTT.2011.111006

Nundy, S., Dick, J. J., Solomon, M. C., \& Peek, M. E. (2013). Developing a behavioral model for mobile phone-based diabetes interventions. Patient Education and Counseling, 9o(1), 125132. https://doi.org/10.1016/j.pec.2012.09.008

Pamungkas, R. A., Chinnawong, T., \& Kritpracha, C. (2015). The effect of dietary and exercise selfmanagement support program on dietary behavior exercise behavior and clinical outcomes in muslim patients with poorly controlled yype $2 \mathrm{DM}$ in a community setting in Indonesia. Nurse Media Journal of Nursing, 5(1), 1-14. https://doi.org/10.14710/NMJN.V5I1.10186

Peimani, M., Rambod, C., Omidvar, M., Larijani, B., Ghodssi-Ghassemabadi, R., Tootee, A., \& Esfahani, E. N. (2016). Effectiveness of short message service-based intervention (SMS) on self-care in type 2 diabetes: A feasibility study. Primary Care Diabetes, 10(4), 251-258. https://doi.org/10.1016/j.pcd.2015.11.001

Peiris, D., Praveen, D., Johnson, C., \& Mogulluru, K. (2014). Use of mHealth systems and tools for non-communicable diseases in low- and middle-income countries: A systematic review. Journal of Cardiovascular Translational Research, 7(8), 677-691. https://doi.org/10.1007/s12265-014-9581-5

Pesantes, M. A., Del Valle, A., Diez-Canseco, F., Bernabé-Ortiz, A., Portocarrero, J., Trujillo, A., Cornejo, P., Manrique, K., \& Miranda, J. J. (2018). Family support and diabetes: Patient's experiences from a public hospital in Peru. Qualitative Health Research, 28(12), 1871-1882. https://doi.org/10.1177/1049732318784906

Powers, M. A., Bardsley, J., Cypress, M., Duker, P., Funnell, M. M., Fischl, A. H., Maryniuk, M. D., Siminerio, L., \& Vivian, E. (2017). Diabetes self-management education and support in type 2 diabetes: A joint position statement of the American Diabetes Association, the American Association of Diabetes Educators, and the Academy of Nutrition and Dietetics. The Diabetes Educator, 43(1), 40-53. https://doi.org/10.1177/0145721716689694 
Rahmah, G. N., Sukartini, T., \& Utami, S. (2019). Factors associated with patients' adherence to self-care behaviors among patients with diabetes mellitus: A literature review. International Journal of Nursing and Health Services (IJNHS), 2(4), 205-212. https://doi.org/10.35654/ijnhs.v2i4.144

Rathbone, A. L., \& Prescott, J. (2017). The use of mobile apps and SMS messaging as physical and mental health interventions: Systematic review. Journal of Medical Internet Research, 19(8):e295. https://doi.org/10.2196/jmir.7740

Richard, A. A., \& Shea, K. (2011). Delineation of self-care and associated concepts. Journal of Nursing Scholarship, 43(3), 255-264. https://doi.org/10.1111/j.1547-5069.2011.01404.x

Rudijanto, A., Soewondo, P., Waspadji, S., Yunir, E., \& Purnamasari, D. (2011). The Indonesian society of endocrinology's summary article of diabetes mellitus national clinical practice guidelines. Journal of the ASEAN Federation of Endocrine Societies, 26(1), 17-19. https://doi.org/10.15605/jafes.026.01.03

Sayeed, K. A., Qayyum, A., Jamshed, F., Gill, U., Usama, S. M., Asghar, K., \& Tahir, A. (2020). Impact of diabetes-related self-management on glycemic control in type II diabetes mellitus. Cureus, 12(4), e7845. https://doi.org/10.7759/CUREUS.7845

Sh, S., Hsu, Y. Y., Toobert, D. J., \& Wang, S. T. (2019). The validity and reliability of the summary of diabetes self-care activities questionnaire: An Indonesian version. Indonesian Nursing Journal of Education and Clinic (INJEC), 4(1), 25-36. https://doi.org/10.24990/INJEC.V4I1.229

Shipman, D., \& Durmus, B. (2017). The effect of culture on food consumption: A case of special religious days in Turkey. Journal of Food Research, 6(2), 92. https://doi.org/10.5539/jfr.v6n2p92

Sujarwo, W., Caneva, G., \& Zuccarello, V. (2020). Patterns of plant use in religious offerings in Bali (Indonesia). Acta Botanica Brasilica, 34(1), 40-53. https://doi.org/10.1590/010233062019 abbo110

The Central Bureau of Statistics of Indonesia. (2018). Indonesian statistics telecommunication 2017. https://www.bps.go.id/publication/2019/12/02/6799f23db22e9bdcf52c8e03/ statistik- telekomunikasi-indonesia-2018.html

Toobert, D. J., Hampson, S. E., \& Glasgow, R. E. (2000). The summary of diabetes self-care activities measure: Results from 7 studies and a revised scale. Diabetes Care, 23(7), 943-950. https://doi.org/10.2337/diacare.23.7.943

Van Olmen, J., Kegels, G., Korachais, C., de Man, J., Van Acker, K., Kalobu, J. C., Van Pelt, M., Ku, G. M., Hen, H., Kanda, D., Malombo, B., Darras, C., \& Schellevis, F. (2017). The effect of text message support on diabetes self-management in developing countries - A randomised trial. Journal of Clinical \& Translational Endocrinology, 7, 33-41. https://doi.org/10.1016/J.JCTE.2016.12.005

Venkataraman, K., Kannan, A., \& Viswanathan, M. (2009). Challenges in diabetes management with particular reference to India. International Journal of Diabetes in Developing Countries, 29(3), 103-109. https://doi.org/10.4103/0973-3930.54286

WHO. (2016). Global report on diabetes WHO library cataloguing in publication data global report on diabetes. https://apps.who.int/iris/bitstream/handle/10665/204871/9789241565257_eng.pdf?sequ ence $=1$

WHO. (2018). Non-communicable diseases country profiles 2018. https://apps.who.int/iris/handle/10665/274512 